\title{
Erratum to: Impaired health status and care dependency in patients with advanced COPD or chronic heart failure
}

\author{
Daisy J. A. Janssen - Frits M. E. Franssen • \\ Emiel F. M. Wouters • Jos M. G. A. Schols • \\ Martijn A. Spruit
}

Published online: 3 April 2012

(C) Springer Science+Business Media B.V. 2012

Erratum to: Qual Life Res (2011) 20:1679-1688

DOI 10.1007/s11136-011-9892-9

The electronic supplementary material was missing in the original publication. Please find it published online with this erratum.

The online version of the original article can be found under doi:10.1007/s11136-011-9892-9.

Electronic supplementary material The online version of this article (doi:10.1007/s11136-012-0165-z) contains supplementary material, which is available to authorized users.

D. J. A. Janssen $(\bowtie) \cdot$ F. M. E. Franssen .

E. F. M. Wouters - M. A. Spruit

Program Development Centre, CIRO+, Centre of Expertise for Chronic Organ Failure, Hornerheide 1, 6085 NM Horn,

The Netherlands

e-mail: daisyjanssen@proteion.nl

D. J. A. Janssen

CAPHRI, Maastricht University, Maastricht, The Netherlands

D. J. A. Janssen

Proteion Thuis, Horn, The Netherlands

E. F. M. Wouters

Department of Respiratory Medicine, Maastricht University

Medical Centre+ (MUMC+), Maastricht, The Netherlands

J. M. G. A. Schols · M. A. Spruit

Department of General Practice, Nursing Home Medicine, Faculty of Health Medicine and Life Sciences/CAPHRI,

Maastricht University, Maastricht, The Netherlands 